intercellular fibrous tissue they gradually shrink, and so in the end the liver becomes both small and hard-cirrbosed. Strumpell, while attributing the cirrhosed condition of the liver to the deleterious effects of uric acid upon its parenchyma adopts Scudamore's riew that gout is the cause and not the effect of liver disease. Murchison said gout induced jaundice, gall stones, and biliary catarrhs. The majority of our contemporary pathologists, however, think that the gout springs from the liver disease and not the liver disorders from the gout. Trousseau even went further, for when I attended his lectures he told us that gout was not in itself a disease, but only a sign and symptom of liver derangement, in the same way as the eruption in small-pox is not the disease, any more than the sore throat of scarlet fever, but a mere symptomatic manifestation of a constitutional morbid state. I am not quite prepared to endorse so sweeping a theory, for though I admit the existence of several clinical facts strongly pointing in its direction I do not think that they are sufficiently conclusive to warrant its unreserved adoption.

In his Croonian Lecture at the Royal College of Physicians of London in 1886 Professor Latham also cilled attention to the close intimacy existing between gout and liver derangements. Indeed, it is impossible for anyone who has given attention to the subject not to be impressed with it, and any one who has kept notes of gout cases will see by referring to them that by far the majority of the patients have been bilious subjects. Not only so, but if he has had many severe gout cases he will also be forced to believe that not only is uric acid gravel, but diabetes a very common accompaniment of gout. This is only what might be expected, seeing that uric acid calculi are almost invariably associated with liver derangements; and there is a special form of diabetes depending upon liver disorders known under the title of hepatic diabetes, just as there is one of albuminuria, known as hepatic albuminuria. ${ }^{4}$

Murray Forbes said that gout, diabetes, renal calculi, gallstones, and jaundice may all occur in the same patient. In order that the reader may not suspect me of manufacturing a case to confirm the statement, I shall furnish him with one whose authority is beyond dispute, seeing that it is none other than that of the renowned Scottish novelist, Sir Walter Scott, extracted from his own Diary, ${ }^{5}$ and thereby rendered all the more valuable from the fact that the account he gives of his clinical history is alike unbiased by medical dogma and personal theory, for he was a lawyer and not a medical practitioner.

Sir Walter tells how he had to diminish the use of alcohol "for fear of a weakness in the direction of diabetes, a disease which broke up my father's health." He also says he "was seized with a most violent pain in the right kidney," which Dr. Clarkson diagnosed as renal "gravel augmented by bile."

In Lockhart's life of Scott it says he occasionally suffered agonising pain from the passing of gall-stones accompanied with jaundice. Sir Walter himself describes more than one of "these excruciating attacks." Moreover in various parts of his Journal Scott refers to the violent attacks of gout he had at different times in his feet, knees, gums, and back, comparing the pain to a "scorpion's bite," and its intensity as being sufficient to make him "howl."

As is the case with most "livery" subjects Sir Walter Scott was subject to fits of great mental depression. Alluding to one of these in 1826 he says it was accompanied by "a fluttering of the heart" and a feeling as if he "knew not what was going to befall " him

Like many other gouty and "livery" people Sir Walter Scott ultimately died from apoplexy, so that his is a most instructive case of hereditary liver derangement, associated with gout, diabetes, renal calculi, and gall-stones, and ending in apoplexy.

When all the foregoing hepatic pathological data are considered it is evident that gout in different people must require entirely different forms of treatment. And in order to treat a case philosophically each individual constitutional peculiarity must be prescribed for quite as carefully as the special condition denominated gout, for while one patient may be benefited by colchicum it may on another act as a poison. Carbonated alkali does good to one, and iodide of potassium acts like magic on another; whereas, as

+ Diabetes : Its Various Forms and Different Treatments; Albuminuria, with and without dropsy, by the writer. Walton and Maverley, London, 1872 .

Sir Walter Scott's Journal, Douglas, Edinburgh, 1890.
Scudamore discovered, many require their livers to be set to rights before any gout remedy whatever is of the slightest use. This is one of the reasons why several of the vegetable purgatives, in combination with quinine and digitalis, have been vaunted by some of our continental confrères, and mineral waters by others as podagra specifics. But the curative effects of both the one and the other of them spring mainly, I believe from their hepatic action. Piperazin, salicylate of soda, diuretin, and guaiacum are all useful in certain cases. Exactly in the same way different gouty constitutions tolerate different wines. It may, however, be laid down as a general rule that the less acid and the less alcoholic a wine is the less likely is it to disagree with a gouty patient. Hence it is that the sour forms of champagne at present sold in England should in all cases be shunned, no matter what one is told by the uninitiated to the contrary. Champagnes such as the French themselves drink are the safest, for that sugar gires gout is alike contrary to scientific observation and everyday practical experience.

Again while hot applications with anodyne liniments and hot alkaline fomentations are of marked benefit to some, I know from personal experience that ice applied to the painful part until the skin over it is frozen will occasionally give immediate relief. Massage again, either moist or dry, when it can be tolerated often greatly expedites the cure.

Gout is such a protean form of disease that no special line of treatment can be formulated for it as a whole, each constitution and each individoal paroxysm requires to be treated according to its own special conditions.

Harley-street, W

\section{GANGRENE OF THE LEG IN PUERPERAL WOMEN, WITH SEVERE PAIN IN, AND ANALGESIA OF, THE AFFECTED}

\section{LINB.}

\section{By THOMAS OLTTER, M.A. Durh., M.D. GLasG.,} H' R.C.P. LOND.

PHYSICIAN TO THE ROYAL INFIRMARY, NEWCASTLE-UPON-TYNE.

OF the accidents which befall women in, or shortly after, their confinement, and which are not immediately fatal, I know of none more painful to the patient or more disappointing to the friends than blocking of a large artery at some distance from the heart and the consequences which follow. It has been my fortune within the last few months to have seen in consultation with medical friends two such cases of sudden blocking of the popliteal artery, and as this happily is rather an uncommon complication of the puerperal period, many obstetricians of even large experience never having observed it, the rarity of the event, the extremely painful nature of the illness, and its anxious character are my excuse for bringing the following details before the notice of the profession.

CASE 1. Riyht braclioplegia with transitory difficulty of speech occurring fourtetn days after confinement; popliteal thrombosis; gangrene of foot and leg; amputation: recovery. - A married woman aged twenty-three years, a healthy primipara, was delivered by Dr. Leech of Newcastle on October 1st. The confinement was normal. Fourteen days afterwards, when up and apparently quite well, she fainted and would have fallen. On being placed in bed it was noticed that she had lost the power of her right arm, that the corresponding side of her face was slightly paralysed, and subsequently that she had great diffisulty in speaking. The right leg was not affected. Next day the paralysis of the arm had, practically speaking, disappeared, but in the evening she complained of severe pain and numbness in her right foot and in the calf of the leg. Within a few hours after this the big toe had become gangrenous and a dusky erythematous patch was present on the lowest two-thirds of the leg. Next morning, when I saw her with Dr. Leechthat is, the third day after the fainting and the second after the pain in the foot-the pulse was 104, and the temperature $99^{\circ} \mathrm{F}$. Speech had returned, the pupils were normal, there was no longer any facial paralysis, and the brachioplegia had disappeared. The right leg was gengrenous; it was bluish.black three inches above the ankle, whilst the big toe was perfectly black and covered with large blebs, some of which contained bloody fluid and 
others serum. The skin of the leg elsewhere was the skin over the instep showed a few small hemorrhages. extremely pale and cold; the veins were small and no pulsation could be felt in the arteries at the ankle. The leg was painful on morement and yet there was complete loss of the sensation of touch and pain, as tested by the prick of a pin as far upwards as two inches abore the knee-joint. Pain, too, was complained of along the course of the large arteries and veins. It was a moist gangrene, there being large blebs as high up as the top of the calf. The left leg appeared to be normal although the patient complained of pain in the heel. The urine was free from albumin. The sounds of the heart were healthy. They were perhaps a little louder than usual, but the organ was beating rather vigorously. Stimulants were repeated; a mixture of digitalis and ammonia was ordered and external heat carefully applied. Two days afterwards, as the gangrene was spreading rapidly, it was decided at our consultation, even in the absence of a distinct line of demarcation, to amputate the limb. Dr. Leech, assisted by Dr. Metcalfe, there and then removed the limb, amputating it about three inches above the knee-joint. The anxsthetic was well borne. On cutting open the leg subsequently both the popliteal artery and veins were found to be filled with clot, that in the artery reaching up to within a very short distance of the lower border of the incision made through the skin at the operation. The patient, after rallying from the shock, made an excellent recovery and in a letter received some months afterwards from Dr. Leech he informed me she was then moving about quite well by means of a crutch and that her general health was good.

CASE 2. Pneumonia four days after confinement; endocarditis followed by embolism of the right popliteal artery; gangrene; amputation of leg; death nineteen days afterwards from a recurrence of pneumonia and exhaustion.-At midnight on January 25th of this year I was requested by Mr. Galbraith of Gosforth to see with him a married woman aged twenty-five years who had been delivered of ber second child on the 14th. The infant had been born before the medical attendant arrived. The nurse who separated the child from the mother had allowed the patient to remain uncovered for a time and to lie in the wet. On his arrival Mr. Galbraith found the patient cold and inclined to shiver. The placenta which was lying in the vagina was at once removed. Nothing of any moment followed within the next three days, but on the 18th there were signs of pneumonia in the right lung; the temperature had risen suddenly to $103.5^{\circ} \mathrm{F}$. and the pulse to 120. The patient for the next few days progressed as favourably as could be expected. On the 23rd the sputa were rusty, and next morning the expectoration was bloody, but not abundantly so. In the course of the afternoon of the 24th she was suddenly seized with pain of an excruciating character in the calf of the right leg, but as nothing could be seen or felt in it, the limb was carefully covered and gentle heat applied to it. It was early morning on the 26th when I saw her with her medical attendant. The pain in the leg for the previous thirty hours had been very severe. We found the patient propped up in bed in a semi-recumbent position looking extremley ill; her eyes were large and staring. She was worn out for want of sleep and was exhausted by pain. Her respirations were 30 to the minute, the face was flushed and slightly cyanosed, and she was perspiring freely. The tongue was moist and clean. The bowels had been moved on the previous day. The temperature was $103^{\circ}$ and the pulse 138. The heart was beating rery excitedly; its impulse was diffused. Over the mitral area a loud, rough systolic murmur could be heard and some pericardial grating, whilst at the aorta the sounds were normal. The left lung, which was dull on percussion, was the seat of small crepitating râles, heard almost from the apex to the base at the back and front. Small crepitation was also heard over the base of the right lung. The abdomen presented nothing abnormal. A vaginal examination was not considered necessary. The lochia had ceased three days before this, but there had been nothing peculiar about it, no odour, \&re. There was milk in the breasts. The right leg was very pale and cold to the touch. The right calf was swollen and measured twelve and a quarter inches, whilst the left w is eleven inches. No pulsation could be felt in the lower part of the popliteal space; there was none on either side of the ankle, and very little high up in the popliteal artery itself. There was complete anæsthesia of the skin from the sole of the foot to two inches and a half above the knee joint. On the sole of the right foot there were two or three large, bluish-red circular patches with a pale centre, and Here and there all over the foot and the lower part of the leg there were numerous small spots like purpura hæmorrhagica. As the patient was suffering from shock and loss of sleep through pain we decided to continue the stimulants she was taking, to maintain as far as possible the heat of the limb by covering it with cotton wadding, to administer opium to procure sleep and relieve pain, to quieten the heart and improve the circulation by means of a digitalis, ammonia, and spirit of chloroform mixture, and to administer strong soups, all in the hope of rallying her and placing her in the most favourable condition for having the limb removed when possible. The opium gave the much-needed rest and the treatment answered satisfactorily. When I saw her again on the 27th she looked better; she was now able to talk more freely owing to the breathing having been relieved. She had slept well the previous day, but that morning the pain had returned with undiminished severity below the knee. Her temperature was $100^{\circ}$, her pulse was 100 and of better volume. The left lung was clearer and there were fewer râles in it. The heart was beating more steadily, but the mitral systolic murmur was still very loud and rough and heard well at the inferior angle of the left scapula. Sensation and warmth had returned to the right leg to two inches below the knee-joint, but all below this was insensitive to the prick of a pin and was icy cold. The bluish patches already mentioned had extended. The lochia had returned and was healthy though scanty. The urine was examined and found to be quite free from albumin and sugar. On the 28th the pain in the leg was extremely severe; it was referred to the popliteal region just above the knee and was deeply situated. The gangrenous patches had extended; the pulse was 130 and the temperature $102^{\circ}$, whilst the tongue remained moist and clean in spite of large doses of opium given to relieve her sufferings. The right calf was still increasing in size; it now measured thirteen inches. The lungs were improving, but the mitral systolic murmur was still very loud, whilst over the aortic area for the first time a soft systolic murmur was heard, followed by a loud accentuated second sound. It was now evident that unless the limb was removed she could not recover. The gangrene was rapidly extending, and as she had rallied as much as she possibly could and would under the circumstances Dr. Hume, who consulted with us, confrmed our opinion as to the advisability of the amputation and removed the leg a few inches above the knee, Mr. Galbraith administering the anæsthetic. She took the anæsthetic (A.C.E mixture) well. The operation of itself was quite successful. On dissecting the leg $I$ found in the popliteal artery a large firm clot extending into the two bifurcations of the vessel The interior of the clot was decolourised. There was no redness of the endarterium. All the reins of the leg contained dark clotted blood. The gangrenous skin on being cut into exhibited a greyish-brown discolouration, with here and there numerous small black clots. The soleus muscle when sliced was seen to be swollen, soft, and watery; it was the seat of numerous small hæmorrhages and even its minutest blood vessels were filled with black clot. The muscle evolved a very strong putrefactive odour. The blood clot in the popliteal artery after careful staining did not reveal the presence of any microbes. The failure to detect them is no proof of their non-existence. Five days after the operation when I again saw the patient there was some sloughirg of the skin flaps. The operation had given her all the relief that we had hoped for, and clearly it had given her the only chance of recovery. The progress of the case, howerer, had not been quite so satisfactory as we had desired. From the sloughing of the surface of the wound and the putrefactive odour in the room it was apparent that there were dangers ahead. I did not see her again, but I learned that the pulmonary symptoms returned, her temperature rose, and that she died from sheer exhaustion and pneumonia probably septic, on Feb. 17th, nearly three weeks after the operation.

In these two cases of rapidly extending gangrene of the leg occurring in lying-in women three points stand out prominently - viz., rascular obstruction, agonising pain, and analgesia and anæsthesia of the affected limb. In the first case the suddenly developed brachioplegia and rapid recovery suggest a slight cerebral thrombosis, whilst the sudden vascular obliteration followed by gangrene of the foot and leg were probably consequent upon the action of a poison causing clotting of the blood. As regards the second patient, of the state of whose heart 
anterior to her last confinement we have no knowledge, it is probable, assuming that organ to have been healthy, that the pneumonia which developed within the first week after her delivery was septic, that it was followed by endocarditis of an ulcerative character, and that from the valres of the heart vegetations were carried into the right popliteal artery causing sudden blocking of the ressel. The veins of the affected limb in each instance were filled with clot. Under ordinary circumstances simple arterial blocking would of itself scarcely cause such rapidly developing gangrene. The other points of interest are the severe pain in the foot and leg generally, the complete loss of the sense of touch and pain in the skin, not only of the foot, but of the leg, for three inches above the knee-joint-i.e., above the location of the clot in the artery. We can readily understand how in a foot, the toes of which are blackening with gangrene and whose skin is bullous, there should be loss of sensation; but why arterial obstruction below the knee should be so quickly followed by absolute loss of the sensation of touch, heat and pain in the skin of the limb above as well as below the point of arterial obliteration, and why surface analgesia should be associated with agonizing pain in the affected foot and in the leg generally, are circumstances not so readily explained. The sudden and complete loss of the sense-receptivity of the nerve-endings in the skin over such a large area suggests a central lesion, for in the earliest stages it seems to have been too diffused to have been due to a peripheral cause, and yet the severe pain suggests the probability of the latter. If so, then to what must the pain be attributed? It was in 1858 that Charcot drew attention to "claudication intermittente des extremités" as an explanation of the severe pain which occurred in a peculiar illness occasionally observed amongst men and women and which was at times followed by gangrene necessitating amputation of the limb. Charcot got the phrase from Bouley and applied it to the disease in question. Bouley had observed horses become suddenly affected in their hinder extremities so that they limped and seemed to be in great pain. If when in this condition they were whipped the animals would fall down apparently in acute suffering, not from the effects of the lash, however, for there was distinct anæsthesia of the surface associated with rigidity of the limb. These phenomena would quickly disappear and the animal shortly afterwards would seem quite well, but if again whipped the phenomena returned. When a horse under these circumstances was killed the main artery of the affected limb, or the abdominal aorta if both legs had been involved, was observed to be obliterated, either by a thrombus or by pressure of a tumour from without. In cases such as these it was maintained that sudden occlusion of the artery by depriving the muscles of the limbs of their normal nutriment threw them into a state of extreme spasm, or that the waste products accumulating in the muscles had so irritated their nerve-endings that reflexly the muscles passed into a state of extreme contraction. On the theory, therefore, of severe muscular cramp Bouley songht to explain the severe pain, and to some of the readers of this paper it might seem as if this was the explanation of the acute suffering that occurred in these cases of puerperal gangrene. Pain in a limb affected by commencing gangrene may be paroxysmal, but muscular spasm has not seemed to me to be a likely explanation of it. In neither of the two cases just reported could I detect anything like rigidity or hardening of the muscles under the hand. The pain was occasionally felt in the foot or diffused over the limb generally ; sometimes it was several inches above the site of rascular obstruction, sometimes it was below it. Whilst, therefore, admitting muscular spasm or "claudication intermittente" as a possible explanation of the pain it is not sufficient. The severity of the deep-seated pain and the loss of surface sensibility suggest a nervous lesion-e.g., a rapidly developing peripheral neuritis, or that there may have been irritation of nerve-endings in the walls of bloodressels, which in gangrene are known to be in a state of extreme contraction.

There is now recognised, thanks to the labours of Lanceraux and others, a form of gangrene described as neuropathic in which patients, after complaining for years of pain in a limb, have gladly submitted to removal of the offending member for relief to pain which is so exhausting as to have caused death, and when amputation has not been performed the illness has been followed by gangrene. There are practically the same symptoms as in "claudication intermittente " and on cutting up the limb the appearances presented by the muscles closely resemble those observed in my own cases of puerperal gangrene. The arteries, however, are found to be thickened at their extremities whilst at other places they are free, but the nerve centres and nerve trunks are the seat of the pathological changes met with in neuritis. One feature said to be specially characteristic of this neuropathic form of gangrene is the long-continued pain. Whilst the gangrene of puerperal women is distinguished from the neuropathic form by the absence of the long-continued prodromal period of pain, is sudden in its onset, and is of rapid development, for the foot and leg become gangrenous in a few hours, also that the gangrene is rather moist than dry, the nerves, in spite of their connexion with the nutritional centres in the spinal cord, become rapidly affected, the morbid changes resembling those met with in inflammation followed by degeneration. Why they become thus affected it is difficult to say, but it is probable that in the rapid death en masse of the tissues that surround the terminations of peripheral nerves their endings, no longer perfectly nourished from the centres and being in the midst of death, also die and in the act of dying cause pain. It is impossible to exonerate altogether the walls of the bloodressels. These were healthy on microscopical examination, but the artery itself was firmly contracted upon the contained clot, and pain of a severe nature is not unknown in cases where arteries are in a state of extreme contraction or spasm.

The analgesia and anæsthesia of the skin deserve a word or two in passing although difficult of explanation. This loss of surface sensibility has received considerable atten tion from Sherrington, Herringham, Head, Patterson, and Mackenzie of Burnley. It is now admitted that the muscles of a given part of a limb and the overlying integument are not necessarily supplied by the same segmental nerves. 1 Segmental areas of skin are not supplied by their respective posterior spinal nerve roots, but "represent rather the parts of the skin in connexion with the segments of the grey matter of the spinal cord by means of fibres subserving the sensations of pain, heat, and cold, but not touch." How does this affect the question of occlusion of an artery being followed by loss of sensation in the skin? As the analgesia was present in both of my puerperal patients the possibility of bysteria bas only to be mentioned to be at once set aside. The circumstance suggests problems to those who are still working in this line of research, for the areas of anæsthesia in my cases corresponded to the field of distribution of possibly the lower portion of the second lumbar nerve, and the third, fourth, and fifth lumbar nerves. It is now recognised that the large arteries of the body, like the abdominal viscera, are supplied by sensory fibres passing through the sympathetic system; hence the pain complained of might, as we have said, be due to changes produced in the walls of the arteries. There was nothing in my cases, at any rate, to support the theory of Ross of "referred pain," for the pain was not referred to areas from which one special set of sensory nerve fibres was proceeding. I can offer no adequate explanation of the loss of sensation of touch and pain over such a large area of the skin. This other fact, however, is apparent-that once complete occlusion of the popliteal artery occurred, then owing to the unhealthy blood and weakened tissue resistance, aggravated by increasing cardiac debility, the affected limb exposed to the influence of the air became a ready prey to putrefactive microbes, which, rapidly multiplying, extended through the tissues causing numerous sero-hæmorrhagic exudations, accompanied by considerable formation of gas, and to this external circumstance as well as to morbid internal states must be attributed the rapid spread of gangrene in these women after their confinement.

Newcastle-on-Tyne.

Quain, vol. iii., part ii., p. 350.

British Balneological aNd Chimatological SOCIETY.-An ordinary meeting of this society was held at Limmer's Hotel on Wednesday, June 17th, the President, Dr. Henry Lewis (Folkestone), being in the chair-Dr. Theodore Williams gave an address on Sea Bathing and the Open-air Treatment of Disease. The address led to a discussion, in which the Chairman, Dr. William Ewart, Dr. Sansom, Mr. Haviland (Donglas), Dr. Snow (Bournemouth), Dr. Myrtle (Harrogate), Dr. G. Bennet (Buxton), Dr. Symes Thompson, and Dr. Gilbert (Tunbridge Wells) joined, and was followed by a very successful cunversazione. 